\title{
AÇÃo DE Eleusine coracana NA REMEDIAÇÃo DE Solos Contaminados com Picloram ${ }^{1}$
}

\author{
Action of Eleusine coracana in the Remediation of Soils Contaminated with Picloram
}

\author{
SILVA, L.O.C. ${ }^{2}$, SILVA, A.A. ${ }^{3}$, QUEIROZ, M.E.L.R. ${ }^{4}$, LIMA, C.F. ${ }^{4}$, ROCHA, P.R.R. ${ }^{5}$ e \\ D’ANTONINO, L. ${ }^{6}$
}

\begin{abstract}
RESUMO - A evolução do método químico de controle das plantas daninhas tem sido fundamental para o cultivo de grandes áreas com custos de produção compativeis com os mercados nacional e internacional. Atualmente, os herbicidas representam cerca de 45,0\% de todos os agrotóxicos consumidos no Brasil. Esses compostos, em sua grande maioria, podem apresentar longa persistência no ambiente e contaminar o solo, impedindo novos cultivos, e também as águas superficiais e subterrâneas, gerando como consequência problemas ambientais. Objetivou-se com este trabalho quantificar, por meio da técnica cromatográfica, a capacidade da espécie $E$. coracana em reduzir a persistência do picloram em dois tipos de solo - um Latossolo Vermelho-Amarelo e um Argissolo Vermelho-Amarelo largamente cultivados com pastagens e culturas no Brasil, contaminados com esse herbicida. Conclui-se que a espécie E. coracana é eficiente na remediação de solos contaminados por esse herbicida, evidenciando o potencial de uso dela em programas de fitorremediação de áreas contaminadas e redução do risco de impacto ambiental, e que os valores da meia-vida do picloram nos solos avaliados são distintos para uma mesma condição climática, o que pode ser ainda mais diferente em campo.
\end{abstract}

Palavras-chave: meia-vida, herbicida, descontaminação do solo, cromatografia a líquido.

ABSTRACT - The evolution of chemical weed control methods has been fundamental to cultivation of large areas where production costs are compatible with national and international markets. Currently, herbicides account for approximately $45.0 \%$ of all pesticides used in Brazil. Most of these compounds present long persistence in the environment, contaminating soil, hindering new crops as well as surface water and groundwater, thus leading to environmental problems. The objective of this work was to quantify, using the chromatographic technique, the efficacy of the species $\boldsymbol{E}$. coracana in reducing picloram persistence in two soils, a Red Yellow Ultisol and a Red Yellow Latosol, treated with this herbicide, and widely cultivated for pastures and crops in Brazil. It was concluded that the species E. coracana is effective in the remediation of soils contaminated by this herbicide, indicating its potential use in programs of phytoremediation of contaminated areas to reduce the risk of environmental impact. Picloram half-life values of the soils evaluated differed for the same weather conditions, probably differing even more under field conditions.

Keywords: half-life, herbicide, soil decontamination, liquid chromatography

\section{INTRODUÇÃO}

O Brasil, nos últimos anos, tornou-se o maior consumidor mundial de agrotóxicos, e os herbicidas representam cerca de $45 \%$ do consumo total (SINDAG, 2009). Em decorrência desse grande uso, tem-se observado preocupação com a contaminação de

Recebido para publicação em 29.5.2011 e aprovado em 24.4.2012.

2 D.Sc., Professora, Núcleo de Química do Instituto Federal de Educação Ciência e Tecnologia do Sudeste de Minas - IFSUDESTEMG, Campus Barbacena; ${ }^{3}$ D. Sc., Professor Associado, Dep. de Fitotecnia, Universidade Federal de Viçosa - DFT/UFV; ${ }^{4}$ D.Sc., Professor Associado, Dep. de Química - DEQ/UFV; ${ }^{5}$ Eng $^{-}-$Agr $^{\circ}$., D.Sc., Bolsista de Pós-Doutorado, CAPES-PNPD, Dep. de Fitotecnia, Universidade Federal Rural do Semi-Árido - UFERSA; ${ }^{6}$ Eng $^{0}-$ Agr $^{\circ}$., D.Sc., DFT/UFV. 
águas superficiais e subterrâneas por poluentes orgânicos (Celis et al., 2005), pois alguns desses produtos podem contaminar o solo, impedindo novos cultivos, e também atingir as águas por escorrimento superficial, além de processos de lixiviação, causando problemas ambientais cuja extensão é dependente da composição do solo, das características físico-químicas do contaminante e das condições climáticas (D’Antonino et al., 2009a; Santos et al., 2010).

Com isso, têm-se buscado alternativas na despoluição de áreas contaminadas por compostos orgânicos; as estratégias propostas devem apresentar eficiência na remoção dos contaminantes, simplicidade na execução, ação em tempo adequado e menor custo (Pires et al., 2003). Nesse contexto, a fitorremediação de áreas poluídas é interessante, do ponto de vista ambiental, devido à utilização de plantas específicas, visando amenizar ou até mesmo despoluir locais contaminados (Coutinho \& Barbosa, 2007). Algumas plantas são capazes de remover poluentes orgânicos e inorgânicos, retirando-os do ambiente e convertendo-os em metabólitos menos tóxicos que se acumulam nos tecidos delas, sendo um processo mais barato e menos destrutivo que a remediação química ou física, embora mais demorado (Kawahigashi, 2009).

O conhecimento dos processos de descontaminação de solos utilizando espécies vegetais é importante, uma vez que os herbicidas são muito utilizados no controle químico das plantas daninhas em culturas de grande importância econômica, apresentando riscos de contaminação do solo e da água. Diversos estudos, com resultados promissores, vêm sendo desenvolvidos visando avaliar a eficácia de plantas na remoção de herbicidas do solo (Coleman et al., 2002; Kawahigashi, 2009; Procópio et al., 2009).

No Brasil, um dos herbicidas de maior uso em pastagens é o picloram (ácido 4-amino3,5,6-tricloro-2-piridinacarboxílico), aplicado normalmente em pós-emergência das plantas daninhas, visando ao controle de espécies dicotiledôneas arbustivas ou arbóreas infestantes de pastagens (Rodrigues \& Almeida, 2005).

Em valores de $\mathrm{pH}$ comuns em solos tropicais utilizados na agricultura, 4,0 a 6,5
( $\mathrm{pH}>\mathrm{pKa})$, o picloram se comporta predominantemente como um herbicida ácido (pKa 2,3), e a maioria de suas moléculas se encontra na forma anionica, sendo repelidas por cargas negativas que estejam presentes nos solos (Oliveira Jr. et al., 2001). Por esse motivo, os herbicidas ácidos são, normalmente, menos sorvidos aos coloides do solo do que os herbicidas neutros ou básicos (Regitano et al., 2001).

Esse composto apresenta, em relação aos demais herbicidas registrados no Brasil, um dos maiores periodos de atividade residual em solos (Santos et al., 2006; D'Antonino et al., 2009a). Isso impede, a curto e médio prazo, o cultivo de determinadas espécies não tolerantes, em áreas onde o composto tenha sido aplicado. Além disso, o maior tempo de permanência e a lixiviação do herbicida no solo implicam maior risco de contaminação do lençol freático (Gomes et al., 2002; D'Antonino et al., 2009a; D’Antonino et al., 2009b).

Devido aos riscos de contaminação ambiental por picloram, alguns estudos vêm sendo realizados objetivando a busca de espécies vegetais capazes de remediar esse herbicida do solo; estudos recentes demonstraram alta tolerância da espécie capim-pé-de-galinhagigante (Eleusine coracana) ao herbicida picloram (Procópio et al., 2008).

De posse dessas informações, objetivouse com este trabalho quantificar, por meio da técnica cromatográfica, a capacidade da espécie $E$. coracana em reduzir a persistência do picloram em dois tipos de solo contaminados com esse herbicida.

\section{MATERIAL E MÉTODOS}

Para realização deste trabalho, foram utilizados vasos de 3,0 litros de capacidade, preenchidos com amostras dos solos Latossolo Vermelho-Amarelo (LVA) e Argissolo VermelhoAmarelo (PVA), coletados na profundidade de 0-20 cm em área sem histórico de aplicação de herbicidas, peneirados em malha de $4,0 \mathrm{~mm}$. A caracterização físico-química das amostras é apresentada nas Tabelas 1 e 2 (Embrapa, 1997).

Antes do preenchimento, os vasos foram revestidos internamente com filme de 
Tabela 1 - Características químicas das amostras de Latossolo Vermelho-Amarelo (LVA) e Argissolo Vermelho-Amarelo (PVA)

\begin{tabular}{|c|c|c|c|c|c|c|c|c|c|c|c|c|c|}
\hline Solo & $\mathrm{pH}$ & $\mathrm{MO}$ & $\mathrm{P}$ & $\mathrm{K}$ & $\mathrm{Al}^{3+}$ & $\mathrm{Ca}^{2+}$ & $\mathrm{Mg}^{2+}$ & $\mathrm{H}+\mathrm{Al}$ & SB & $\operatorname{CTC}(\mathrm{t})$ & CTC(T) & $\mathrm{m}$ & $\mathrm{V}$ \\
\hline & $\left(\mathrm{H}_{2} \mathrm{O}\right)$ & $\left(\right.$ dag kg $\left.{ }^{1}\right)$ & \multicolumn{2}{|c|}{$\left(\mathrm{mg} \mathrm{dm}^{-3}\right)$} & \multicolumn{7}{|c|}{$\left(\mathrm{cmol}_{\mathrm{c}} \mathrm{dm}^{-3}\right)$} & \multicolumn{2}{|c|}{$(\%)$} \\
\hline LVA & 4,6 & 3,4 & 1,3 & 12 & 1,5 & 0,2 & 0,0 & 8,75 & 0,23 & 1,73 & 8,98 & 87 & 3 \\
\hline PVA & 5,6 & 3,3 & 8,1 & 134 & 0,0 & 3,0 & 0,9 & 3,30 & 4,24 & 4,24 & 7,54 & 0 & 56 \\
\hline
\end{tabular}

Tabela 2 - Características físicas das amostras de Latossolo Vermelho-Amarelo (LVA) e Argissolo Vermelho-Amarelo (PVA)

\begin{tabular}{|l|c|c|c|l|}
\hline \multirow{2}{*}{ Solo } & Argila & Silte & Areia & \multirow{2}{*}{$\begin{array}{c}\text { Classificação } \\
\text { Textural }\end{array}$} \\
\cline { 2 - 4 } & \multicolumn{3}{|c|}{$(\%)$} & Muito Argilosa \\
\hline LVA & 61 & 9 & 30 & Argila \\
\hline PVA & 43 & 24 & 33 & \\
\hline
\end{tabular}

polietileno, de forma a não haver perdas por percolação do herbicida. Os solos foram adubados com N-P-K (4-14-8), sendo utilizados 1,25 e $2,50 \mathrm{~kg}$ dessa fórmula para $100 \mathrm{dm}^{3} \mathrm{de}$ PVA e LVA, respectivamente. Essas quantidades foram calculadas com base nas análises dos solos, visando uniformizar a disponibilidade de nutrientes às plantas. Após isso, os vasos foram preenchidos com $2,80 \mathrm{~kg}$ dos substratos, sendo estes umedecidos até próximo à capacidade de campo, fazendo-se a seguir a semeadura, ou não, de E. coracana (10 sementes por vaso). Aos sete dias após a semeadura, quando já havia ocorrido a emergência de E. coracana, aplicou-se o picloram na dose equivalente a $1.920 \mathrm{~g} \mathrm{ha}^{-1}$ nos vasos, com e sem o cultivo da planta, utilizando-se um pulverizador de precisão equipado com dois bicos XR 110.02, espaçados de 0,5 m, mantidos em pressão de $301 \mathrm{~b} \mathrm{pol}{ }^{-2}$, e volume de calda de $200 \mathrm{~L} \mathrm{ha}^{-1}$. Durante o tempo de condução do experimento, os vasos foram mantidos em casa de vegetação, sendo irrigados regularmente, a fim de manter o solo úmido para o crescimento e desenvolvimento das plantas.

Após 24 horas da aplicação do herbicida, realizaram-se as primeiras coletas de amostras dos substratos dos vasos, para determinação da concentração inicial de picloram; as coletas se repetiram em intervalos de 14 dias. Em cada uma dessas coletas, retirou-se todo o solo contido em dois vasos com o cultivo do capim-pé-de-galinha-gigante e em dois sem a espécie. As amostras foram peneiradas em malha de $2,0 \mathrm{~mm}$ e secas ao ar até obtenção de massa constante. Foram realizadas ao todo 15 coletas com a mesma metodologia, correspondendo a um período de 196 dias de avaliação dos teores de picloram nos solos.

A extração do picloram foi feita utilizando a técnica de extração sólido-líquido proposta por Cheng (1969), adaptada, otimizada e validada por Assis (2009), que consistiu em medir uma massa de 2,00 g de solo em tubos plásticos de fundo cônico e tampa rosqueável, adicionar $20,0 \mathrm{~mL}$ de solução extratora $\mathrm{KC1}$ 0,5 $\mathrm{mol} \mathrm{L}^{-1}$, agitar o frasco em agitador vortex por 10 segundos para a formação da suspensão e ajustar o $\mathrm{pH}$ desta para 7,0, com solução $\mathrm{KOH} 0,1 \mathrm{~mol} \mathrm{~L}^{-1}$. Em seguida, submeteu-se o sistema a agitação vertical por 60 minutos e, ao final, ele foi deixado em repouso por 10 minutos. Posteriormente, submeteram-se os frascos à centrifugação por 10 minutos a $2.260 \mathrm{~g}$, para decantação das partículas e limpeza do extrato. Após essas etapas, $1,5 \mathrm{~mL}$ do sobrenadante foi retirado e filtrado em membrana de $0,45 \mu \mathrm{m}$ de poro em vidros vials e analisado por cromatografia líquida de alta eficiência (CLAE). Todas as análises foram realizadas em triplicata.

A determinação do herbicida foi realizada utilizando-se um sistema de cromatografia líquida de alta eficiência, modelo Shimadzu LC 20AT, com detector UV-Vis (Shimadzu SPD 20A) e coluna de aço inox (Shimadzu VP- ODS Shim-pack $150 \mathrm{~mm} \times$ 4,6 $\mathrm{mm}$ d.i.). As condições cromatográficas para a análise foram: fase móvel composta por solução aquosa de ácido acético a $4 \%$ e acetonitrila na proporção de 85:15 (v/v), respectivamente; fluxo de $1,2 \mathrm{~mL}$ min ${ }^{1}$; volume de injeção de $50 \mu \mathrm{L}$; comprimento de onda de $254 \mathrm{~nm}$; e tempo de retenção de aproximadamente oito minutos. 
Os dados obtidos foram submetidos à análise de regressão, sendo a escolha dos modelos baseada no fenômeno biológico e nos coeficientes das equações testados pelo teste t a $5 \%$ de significância.

A meia-vida $\left(t^{1 / 2}\right)$, que corresponde ao tempo, em dias, necessário para que um composto químico tenha sua concentração diminuída pela metade, foi determinada com base na equação exponencial de primeira ordem ajustada aos dados, $\mathrm{C}=\mathrm{C}_{0} \cdot \mathrm{e}^{-\mathrm{kt}}$, em que $\mathrm{C}$ é a concentração após tempo t, e $\mathrm{C}_{0}$, a concentração inicial do herbicida. Essa equação admite que a taxa de degradação é reduzida linearmente com o decréscimo da concentração e, por análise de regressão linear, podese estimar a $t$ 1/2. Essa equação pode ainda ser simplificada assumindo que, quando $\mathrm{C}_{0} / \mathrm{C}_{\mathrm{t}}$ for igual a 2, o ln será igual a 0,693, e a equação de determinação da meia-vida pode ser reescrita como $t \quad 1 / 2=0,693 / k$ (Silva et al., 2007). Dessa forma, o tempo de meia-vida calculado será independente da concentração inicial do composto.

\section{RESULTADOS E DISCUSSÃO}

Nas Figuras 1 e 2 estão representadas as curvas de regressão, as equações e os coeficientes de determinação do LVA e do PVA com e sem cultivo da espécie fitorremediadora. Observou-se que, nos solos cultivados com E. coracana, os teores de picloram foram inferiores aos dos solos não cultivados, evidenciando a capacidade dessa espécie em fitorremediar o herbicida. Resultados semelhantes foram observados por Procópio et al. (2008), os quais observaram a capacidade de remediação por essa mesma espécie utilizando a técnica de bioensaios.

Na Tabela 3 observam-se os valores de meia-vida do picloram nas diferentes condições avaliadas. Verificou-se que E. coracana reduziu em 56,6 e 49\% o tempo em dias para se atingir a meia-vida do picloram no LVA e PVA, respectivamente, em comparação com os solos sem cultivo, confirmando o potencial fitorremediador da espécie.

Os valores obtidos para as meias-vidas dos solos sem cultivo estão de acordo com a literatura, que relata longa e variável persistência

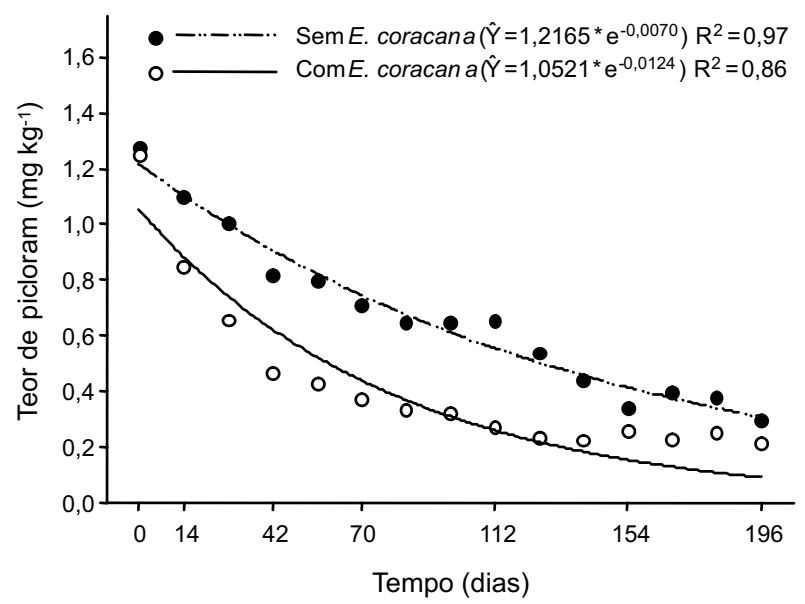

Figura 1 - Teores de picloram no Latossolo Vermelho-Amarelo (LVA), com e sem o cultivo de E. corocana, em função do tempo em dias após a aplicação do herbicida.

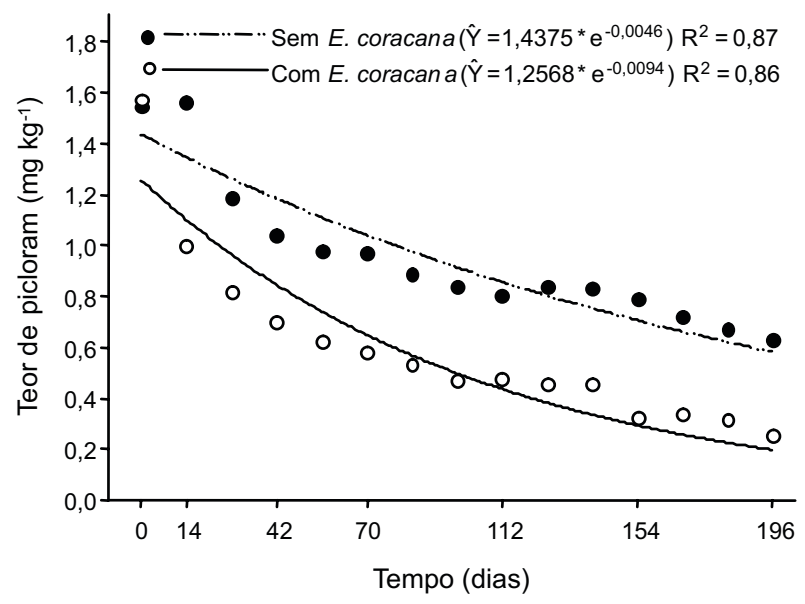

Figura 2 - Teores de picloram no Argissolo Vermelho-Amarelo (PVA), com e sem o cultivo de E. corocana, em função do tempo em dias após a aplicação do herbicida.

Tabela 3 - Meias-vidas $\left(\mathrm{T}_{1 / 2}\right)$ do picloram em Latossolo Vermelho-Amarelo (LVA) e Argissolo Vermelho-Amarelo (PVA) com e sem cultivo de E. coracana

\begin{tabular}{|c|c|c|}
\hline Solo & Cultivo de E. coracana & $\begin{array}{c}\mathrm{T}_{1 / 2} \text { picloram } \\
\text { (dias) }\end{array}$ \\
\hline LVA & Sem cultivo & 99 \\
\hline LVA & Com cultivo & 56 \\
\hline PVA & Sem cultivo & 151 \\
\hline PVA & Com cultivo & 74 \\
\hline
\end{tabular}

do picloram, com meia-vida de 20 a 300 dias, dependendo do tipo de solo e das condições 
ambientais (Pang et al., 2000; Rodrigues \& Almeida, 2005). Santos et al. (2006) encontraram resíduos de picloram no solo até 360 dias após a aplicação, e D’Antonino et al. (2009a), até 150 dias depois da aplicação dos tratamentos, em condições de elevada precipitação pluvial.

Assis (2009) e D’Antonino et al. (2009b) observaram que o picloram apresenta alta sorção e baixa mobilidade em solos com menores valores de $\mathrm{pH}$ e maiores teores de matéria orgânica. No entanto, neste trabalho, o tempo de meia-vida foi maior no PVA em relação ao LVA. Esses solos apresentaram teores de matéria orgânica muito próximos e valores de pH 4,6 e 5,6 no LVA e PVA, respectivamente (Tabela 1). Os solos foram classificados como de textura muito argilosa (LVA) e argilosa (PVA) (Tabela 2).

A diferença nos valores de meias-vidas pode ser atribuída ao fato de que o fenômeno de degradação de herbicidas em solos é complexo, devido à interferência de fatores, como o teor e composição da matéria orgânica, o clima, os minerais do solo e a população microbiana do solo. Esta pode se multiplicar e possuir maior capacidade de degradar o picloram em diferentes condições de $\mathrm{pH}$ do solo (Naik et al., 1972). Esses fatores atuam geralmente juntos - podendo, entretanto, predominar um sobre o outro - e proporcionam a formação da diversidade de características que influenciarão o comportamento dos compostos no solo (Silva et al., 2007). A degradação do picloram ocorre mais rapidamente em temperaturas elevadas, condição comum em regiões tropicais, o que pode favorecer ou não a atividade biológica do herbicida, podendo aumentar a população dos microrganismos do solo. Esse fato pode aumentar a degradação do composto pela microbiota do solo. Além disso, processos como fotodecomposição (Teixeira \& Canela, 2007) e volatilização do composto também devem ser considerados (Ismail \& Kalithasan, 1999).

Carmo et al. (2008) verificaram que um período de cultivo prévio de E. coracana por no mínimo 60 dias reduziu a quantidade de picloram livre no solo e que tempos de permanência superiores não resultaram em aumento da descontaminação na mesma proporção. Esses resultados estão, em parte, de acordo com o observado nas Figuras 1 e 2, onde se verificou tendência à estabilização dos teores de picloram ao longo do tempo, evidenciando que a fitorremediação torna-se menos eficiente após longo período de cultivo. Todavia, vale ressaltar que a alta atividade remediadora de $E$. coracana, estando o picloram disponivel na solução do solo, é extremamente importante do ponto de vista ambiental. Nessa condição, o herbicida estará sujeito à percolação no perfil do solo e, portanto, com alto potencial de contaminação de águas subterrâneas. Quando a concentração do herbicida for muito reduzida no solo, a maior parte desse produto ficará retida aos coloides; assim, a sua lixiviação e os seus efeitos biológicos serão menos significativos. Esses fatos confirmam a importância de $E$. corocana como remediadora de solos contaminados por picloram, o que favorece a liberação mais rápida da área contaminada para novo cultivo de espécies sensiveis ao herbicida e a diminuição do risco de contaminação ambiental.

Conclui-se que a espécie E. coracana apresenta eficiência em acelerar a descontaminação de solos tratados com esse herbicida, evidenciando o potencial de uso dela em programas de fitorremediação de áreas contaminadas por picloram e redução do risco de impacto ambiental, e que os valores da meiavida do picloram nos solos LVA e PVA são distintos para uma mesma condição climática, o que pode ser ainda mais diferente em campo.

\section{LITERATURA CITADA}

ASSIS, E. C. Otimização e validação da técnica ESL para determinção da sorção, dessorção e lixiviação do picloram em solos brasileiros. 2009. 93 f. Dissertação (Mestrado em Agroquímica) - Universidade Federal de Viçosa, Viçosa, MG, 2009.

CARMO, M. L. et al. Influência do período de cultivo do capim-pé-de-galinha-gigante (Eleusine coracana) na fitorremediação de solo contaminado com picloram. Planta Daninha, v. 26, n. 2, p. 601-609, 2008.

CELIS, R. et al. Sorption and leaching behaviour of polar aromatic acids in agricultural soils by batch and column leaching tests. Europ. J. Soil Sci., v. 56, p. 287-297, 2005.

CHENG, H. H. Extraction and colorimetric determination of picloram in soil. J. Agric. Food Chem., v. 17, n. 6, p. $1174-1175,1969$ 
COLEMAN, J. O. D. et al. Exploiting plant metabolism for the phytoremediation of persistent herbicides. Environ. Sci. Poll. Res., v. 9, n. 1, p. 18-28, 2002.

COUTINHO, H. D.; BARBOSA, A. R. Fitorremediação: considerações gerais e características de utilização. Silva Lusitana, v. 15, n. 1, p. 103-117, 2007.

D'ANTONINO, L. et al. Efeitos de culturas na persistência de herbicidas auxínicos no solo. Planta Daninha, v. 27, n. 2, p. 371-378, 2009a

D'ANTONINO, L. et al. Lixiviação do picloram em ArgissoloVermelho Amarelo e Latossolo Vermelho-Amarelo com diferentes valores de pH. Planta Daninha, v. 27, n. 3, p. 589$600,2009 b$.

EMPRESA BRASILEIRA DE PESQUISAAGROPECUÁRIA - EMBRAPA. Centro Nacional de Pesquisa de Solos. Manual de métodos de análise de solos. 2.ed. Rio de Janeiro, 1997. $212 \mathrm{p}$.

GOMES, J. et al. Sorção de atrazina em Cambissolo húmico do Rio Grande do Sul sob vegetação nativa. R. Bras. Ci. Solo, v. 26, n. 2, p. 521-528, 2002.

ISMAIL, B. S.; KALITHASAN, K. Bioactivity, persistence and mobility of picloram in Selangor and Serdang soil series. Pertanika J. Trop. Agric. Sci., v. 22, n. 1, p. 53-61, 1999.

KAWAHIGASHI, H. Transgenic plants for phytoremediation of herbicides. Current Opinion in Biotechnology, n. 20, p. 225-230, 2009.

NAIK, M.N. et al. Microbial degradation and phytotoxicity of picloram and other substituted pyridines. Soil Biol.

Biochem., v. 4, n. 3, p. 313-323, 1972.

OLIVEIRA Jr., R. S. et al. Sorption and leaching potential of herbicides on Brazilian soils Weed Res., v. 41, p. 97-110, 2001

PANG, L. et al. Simulation of picloram, atrazine, and simazine leaching through two New Zealand soils and into groundwater using HYDRUS-2D. J. Contam. Hydrol., v. 44, p. 19-46, 2000 .
PIRES, F. R. et al. Seleção de plantas com potencial para fitorremediação de tebuthiuron. Planta Daninha, v. 21, n. 3, p. $451-458,2003$.

PROCÓPIO, S. O. et al. Efeito da densidade populacional de Panicum maximum (cultivar Tanzânia) na fitorremediação de solo contaminado com o herbicida picloram. Semina: Ci. Agr., v. 30, n. 2, p. 295-304, 2009.

PROCÓPIO, S. O. et al. Fitorremediação de solo contaminado com picloram por capim-pé-de-galinha-gigante (Eleusine coracana). R. Bras. Ci. Solo, v. 32, p. 2517-2524, 2008.

REGITANO, J. B. et al. Atributos de solos tropicais e a sorção de imazaquin. Sci. Agric., v. 58, n. 4, p. 801-807, 2001.

RODRIGUES, B. N.; ALMEIDA, F. S. Guia de herbicidas. 5.ed. Londrina: IAPAR, 2005. 591 p.

SANTOS, L. B. O. et al. Determination of picloram in waters by sequential injection chromatography with UV detection. J. Braz. Chem. Soc., v. 21, n. 8, p. 1530-1536, 2010 .

SANTOS, M. V. et al. Eficácia e persistência no solo de herbicidas utilizados em pastagem. Planta Daninha, v. 24, n. 2, p. 391-398, 2006.

SILVA, A. A. et al. Herbicidas: comportamento no solo. In SILVA, A. A.; SILVA, J. F. (Ed.). Tópicos em manejo de plantas daninhas. Viçosa, MG: Universidade Federal de Viçosa, 2007. p. 189-248.

SINDICATO NACIONAL DA INDÚSTRIA DE PRODUTOS PARA DEFESA AGRÍCOLA - SINDAG.

Dados 2009. Disponível em: <http://www.sindag.com.br> Acesso em: 24 dez. 2010

TEIXEIRA, S.C.G.; CANELA, M.C. Degradação do pesticida Padron ${ }^{\circledR}$ por processos fotoquímicos utilizando luz artificial e solar. Química Nova, v. 30, n. 8, p. 1830-1834, 2007. 